\title{
Theoretical Design of a Leg Module for a Hexapod Underwater Robot
}

\author{
Yazen H. Shakir \\ Department of Systems and Control Engineering, College of Electronics Engineering, Ninevah University, Mosul, Iraq \\ Email address: \\ yazen.mechatronics@gmail.com

\section{To cite this article:} \\ Yazen H. Shakir. Theoretical Design of a Leg Module for a Hexapod Underwater Robot. American Journal of Mechanics and Applications. \\ Vol. 5, No. 1, 2017, pp. 1-7. doi: 10.11648/j.ajma.20170501.11
}

Received: August 23, 2016; Accepted: September 3, 2016; Published: January 7, 2017

\begin{abstract}
In this paper a theoretical design of two degrees of freedom (single leg module) of a hexapod underwater robot is carried out. The length of the two links together is $(30 \mathrm{~cm})$ and the motor for the joint 2 is mounted inside the robot. In addition, forward kinematics analysis is performed to specify angle of movement for each joint by applying Denavit- Hartenberg notation. Furthermore, 3d drawings show the leg implementation. Finally, MATLAB Simulink is used to design PID controller and examine the control signal.
\end{abstract}

Keywords: Hexapod Robot, Leg Design, Underwater Legged Robot

\section{Introduction}

Hexapod robot is a reprogrammable device with six legs which are directly or indirectly attached to the main body of the robot [1]. Those legs are controlled by a number of degrees of freedom that measure the autonomy and allow the robot to move within the environment surrounded to accomplish a particular task. Many studies in the field of legged robots have mainly focused on six legged robot because of some characteristics related to the stability and flexibility of the robot movement. Thus, the importance of studying and analyzing this kind (i.e.: hexapod) is derived from some prevalent strong points, which is possessed by the legged robots in general and the hexapod in particular, that summarized in the table1 below [2-3]:

Table 1. Illustration of the major characteristics of six legged robot.

\begin{tabular}{ll}
\hline The crucial points of studying a six legged robot & \\
\hline \begin{tabular}{ll} 
1- The ability of avoiding obstacles & 4- Variable geometry designs could be made in terms of legs. \\
2- Ease of climbing rough terrain & $\begin{array}{l}\text { 5- Discovering some biological characteristics such as the morphology of living } \\
\text { creatures }\end{array}$ \\
$\begin{array}{ll}\text { 3- The flexibility of selecting criteria of the supporting points on the } \\
\text { ground }\end{array}$ & 6- There is no slip that means the turnabout function disappears during walking. \\
\hline
\end{tabular}
\end{tabular}

A vital aspect of this paper is to propose a leg design for the underwater walking robot. There are several works having been conducted recently in this regard. The contemporary representative underwater robots, little Crabster (which denotes the two words crabs and lobster) underwater robot "LCR200" as a result of modifying Multi-Legged Seabed robot "CR200" has been thorough developed. In [4], "LCR200" leg structure is quite complex, however it is precise because for instance number of sensors inside the leg such as force/ torque sensors.
Two types of joints mechanism can be found in little "Crabster 200". The first one, the motor shaft and the input shaft with harmonic gear are connected indirectly by the pair (pulley -belt) whereas in the second kind the shaft of the motors connects with the other directly ; therefore narrow design and compact is required but the length of the actuator will be long. Figure 1 reveals the final $3 \mathrm{~d}$ implementation of the four degrees of freedom of "LCR200" to cover the complex functions that are walking and swimming in shallow and deep seas. 

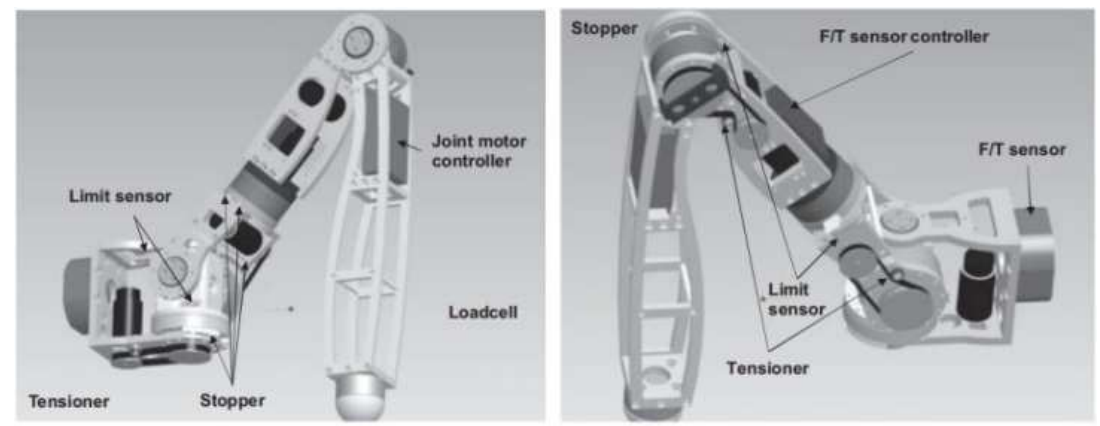

Fig. 1. 3D imensional representation of the little Crabster 200 leg design and the two types of joints as well [4].

Another example of underwater legged-robot has been projected in [5] namely bio-inspired underwater robot. The authors in this research deal with the robot in terms of multi-functionality. Figure 2 displays the inspired design of the leg which enables both swimming and walking capability to the robot. This conceptual design of the leg is inspired by diving beetles. Thus, they state that this design has structural benefits. The passive joint mechanism has been verified in this research.

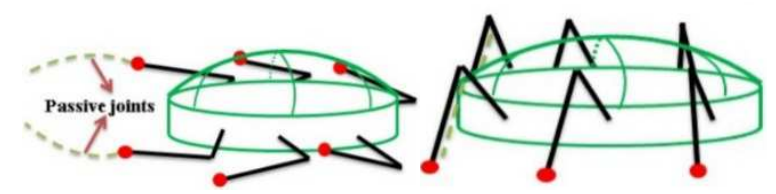

Fig. 2. Walking (right) and swimming (left) modes of the bio inspired robot [5].

The leg design for the robot in Figure 2 can be shown in Figure 3 below:
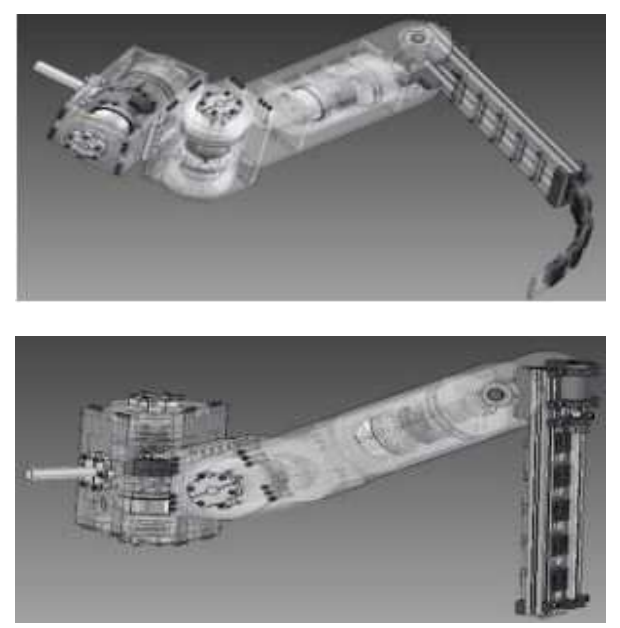

Fig. 3. Walking leg design (bottom) and swimming leg design (top) modes of the bio inspired robot [5].

This paper focuses on building a theoretical design of a two joints leg module of the robot that can walk under the water. A design concept is like a hybrid of taking the advantage of underwater robot design and employ this feature to the six legs walking robot. In other words, the motors of the designed leg must be in the mounting side inside the robot. Consequently, the robot can walk under or above the water. Additionally, this paper comprises controller design to control link 2 of the leg.

\section{The Design Concept}

\subsection{Model Description}

The mechanism that will be designed inspired largely by the spider but in two degrees of freedom. In addition, many researchers enrolled with the underwater inspection robots. This design is a hybrid of mainly walking robot with some features to be added in order to make it active in the water. To this end, worm gear or rack and pinion couple have been applied. The purpose of this type of gear is to achieve the possibility of placing the motor of the second joint away from the joint inside the mounting kit. The design excludes the feet or waterproofing. Figure 4 illustrates the fundamental linkages of the leg design.

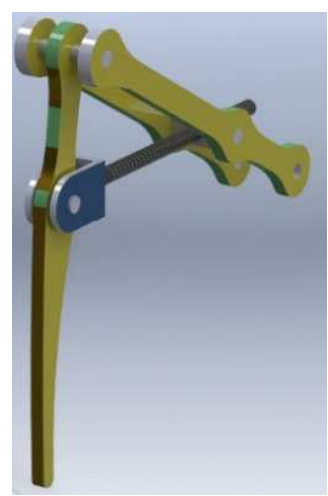

Fig. 4A. Isometric.

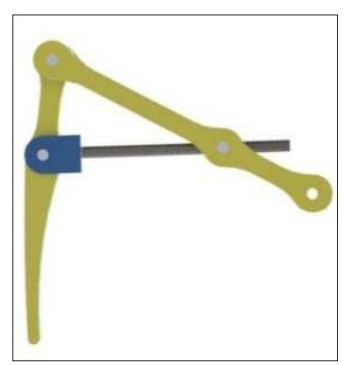

Fig. 4B. Side view.

Figures $4 \mathrm{~A}$ and $4 \mathrm{~B}$ show two views of two degrees of freedom leg module. 


\subsection{Mechanical Considerations}

The mechanical system consists of three main parts. Link 1, link 2 and worm shaft with worm gear as shown below:

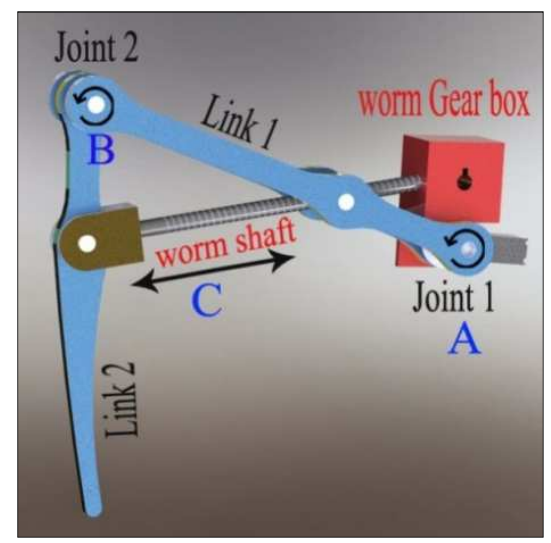

Fig. 5a. Solidworks design with mounting.

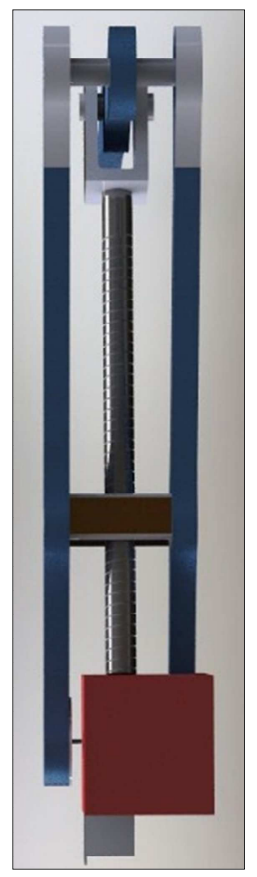

Fig. 5b. Top view.

The underwater walking robot links and joints are:

- A-Joint 1 which actuates the shoulder

- $\quad$ B- The pin joint between Link 1 and Link 2

- C- Worm shaft

The combination actions of $\mathrm{B}$ and $\mathrm{C}$, which are rotation and transition, acts as actuator of the elbow. The worm shaft extends to enter the gearbox as shown in Figure 5 a through the nut as shown in Figure $5 \mathrm{~b}$. the red box in the above picture contains the worm gear and part of the worm shaft. When the motor that is attached to the worm gear rotates the motion converts to linear transition that transfers to the link 2 to obtain remote rotation of joint 2 which is the key aspect of this design. Worm gear has advantages and disadvantages as shown in the table below [6-7]:
Table 2. Advantages vs. disadvantages of using worm gear.

\begin{tabular}{ll}
\hline Benefits of worm gears & Drawbacks of worm gear \\
\hline $\begin{array}{l}\text { Silent and smooth (less noisy than } \\
\text { other gears) }\end{array}$ & It is considered an expensive \\
$\begin{array}{l}\text { Self-locking mode } \\
\text { Reduce speed but increasing the }\end{array}$ & There is high power losses \\
$\begin{array}{l}\text { torque } \\
\text { High velocity ratio }\end{array}$ & Sliding action leads to low efficiency \\
\hline
\end{tabular}

The purpose behind this 2 DOF design is to maximize the payload and to minimize the current drawn due to lightweight aluminum body material. Thus, the inertia will be reduced because of reducing the total mass as much as possible. On the other hand, joint 1 is attached directly with a servo motor.

\subsection{Kinematics Analysis}

1) Applying Forward kinematics by applying DenavitHartenberg notation as shown below:

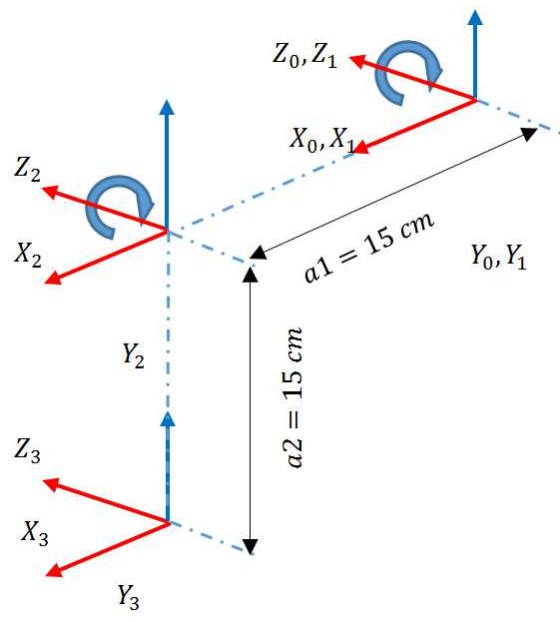

Fig. 6. DH - notation.

Finding DH- parameters: (the index of the T-matrix refers to the joint number).

$$
{ }_{1}^{0} T=\left[\begin{array}{cccc}
\cos \theta_{1} & -\sin \theta_{1} & 0 & 0 \\
\sin \theta_{1} & \cos \theta_{1} & 0 & 0 \\
0 & 0 & 1 & 0 \\
0 & 0 & 0 & 1
\end{array}\right]
$$

$$
\begin{aligned}
& { }_{2}^{1} T=\left[\begin{array}{cccc}
\cos \theta_{2} & -\sin \theta_{2} & 0 & a 1 \\
\sin \theta_{2} & \cos \theta_{2} & 0 & 0 \\
0 & 0 & 1 & 0 \\
0 & 0 & 0 & 1
\end{array}\right] ;{ }_{3}^{2} T=\left[\begin{array}{cccc}
1 & 0 & 0 & a 2 \\
0 & 1 & 0 & 0 \\
0 & 0 & 1 & 0 \\
0 & 0 & 0 & 1
\end{array}\right]
\end{aligned}
$$

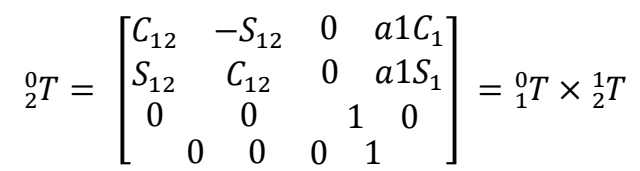

While ${ }_{3}^{0} T={ }_{2}^{0} T \times{ }_{3}^{2} T$. Hence, the final homogenous transformation matrix that describes $\mathrm{DH}$ notation parameters is:

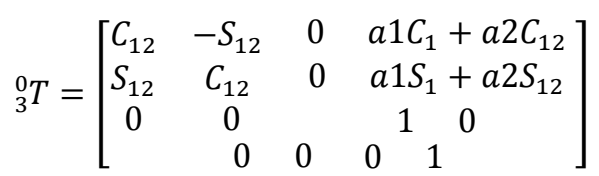




$$
\begin{gathered}
C_{12}=\cos \left(\theta_{1}+\theta_{2}\right)=\cos \theta_{1} \cdot \cos \theta_{2}-\sin \theta_{1} \cdot \sin \theta_{2} \\
S_{12}=\sin \left(\theta_{1}+\theta_{2}\right)=\cos \theta_{1} \sin \theta_{2}-\sin \theta_{1} \cos \theta_{2}
\end{gathered}
$$

Thus, the coordinate system represented by $\mathrm{x}, \mathrm{y}$ and $\mathrm{z}$ can be determined as follow:

$$
\begin{aligned}
& x=a 1 C_{1}+a 2 C_{12} \\
& y=a 1 S_{1}+a 2 S_{12}
\end{aligned}
$$

$z=0$, there is no movement of the two links along Z-axis just along both directions $\mathrm{x}$ and $\mathrm{y}$.

The link parameters for the two links consistent with the leg design in Fig. 5 are exposed in the following table.

Table 3. Advantages vs. disadvantages of using worm gear.

\begin{tabular}{lllll}
\hline \multirow{2}{*}{ Link twist } & $\begin{array}{l}\text { Link length } \\
\boldsymbol{\alpha}_{\boldsymbol{i}-\mathbf{1}}\end{array}$ & $\begin{array}{l}\text { Joint angle } \\
\boldsymbol{a}_{\boldsymbol{i}-\mathbf{1}}\end{array}$ & $\begin{array}{l}\text { Link offset } \\
\left(\boldsymbol{\theta}_{\boldsymbol{i}}\right)\end{array}$ \\
\hline 1 & 0 & 0 & 0 & 0 \\
2 & 0 & $\mathrm{a} 1=15$ & $\theta 1$ & 0 \\
3 & 0 & $\mathrm{a} 2=15$ & $\theta 2$ & 0 \\
\hline
\end{tabular}

2) Implementation of $D H$ notation in MATLAB

Table 4. Joint angles range with calculated values $X$ and $Y$.

\begin{tabular}{lll}
\hline The joint angle $(\boldsymbol{\theta})$ range & X coordinate & Y coordinate \\
\hline $\boldsymbol{\theta}_{1}=-30^{\circ}, \boldsymbol{\theta}_{2}=-90^{\circ}$ & $21.2432 \mathrm{~cm}$ & $-20.0256 \mathrm{~cm}$ \\
$\boldsymbol{\theta}_{1}=-90^{\circ}, \boldsymbol{\theta}_{2}=-150^{\circ}$ & $10.4888 \mathrm{~cm}$ & $-4.2769 \mathrm{~cm}$ \\
\hline
\end{tabular}

The positions of the leg has been extracted from the two joint angles. Then the following is the workspace of the two links leg is revealed as shown in Figure 7.

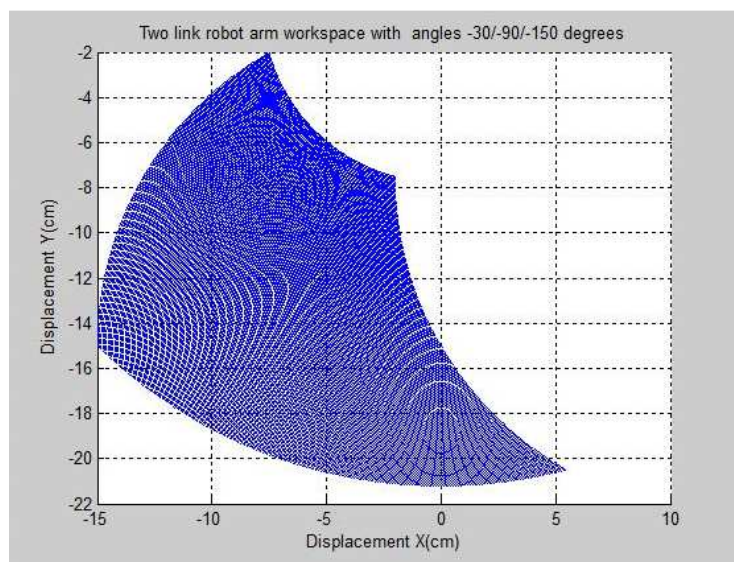

Fig. 7. MATLAB solution of the position workspace.

\subsection{Bill of Materials}

In order to organize the bill of the materials that constitutes the leg module, three separate bills will be created. Firstly, bill of the material of servo motor and its related products is presented. Here, it is necessary to mention that there are two categories of servo motor under which the servo can be classified. Digital servo motor and analogue. There is no difference between the two categories in terms of case, gears and even the feedback wiper of the potentiometer. However, the core difference between them is the feedback signal that is compatible with a data acquisition card. In other words, the processing of the information that is sent to the controller will be dealt differently [8]. Consequently, in this paper the digital

\begin{tabular}{|c|c|c|c|c|}
\hline \multicolumn{5}{|l|}{ Servo motor components for joint 1} \\
\hline Product ID & Brief description & weight (kg) & Qty & Price \\
\hline & $\begin{array}{l}3 \text { poles } \\
\text { Bearing type : Ball }\end{array}$ & & & \\
\hline Hitec HS-5646WP Waterproof, High Torque Digital Servo & $\begin{array}{l}\text { Torque: } 17-19 \\
\text { Speed : } 0.2-0.18 \\
\text { Voltage: } 6 \text { V- } 7.4 \mathrm{~V}\end{array}$ & 0.061 & 1 & $£ 33.7$ \\
\hline HPP-21 Digital Servo Programmer & $\begin{array}{l}>\text { PC Programmer for Hitec digital servos } \\
>4.8 \mathrm{~V} \text { battery \& USB cable required }\end{array}$ & 0.01 & 1 & $£ 16.8$ \\
\hline Arduino Uno USB Microcontroller Rev 3 & $\begin{array}{l}\text { It is intended for roboticists, artists, designers and hobbyists } \\
\text { Variety of I/O pins including analog, digital, PWM and more }\end{array}$ & 0.025 & 1 & $£ 15$ \\
\hline
\end{tabular}
type will be selected because of the modern computerized systems are dealing with digital data.

Table 5a. First bill of material for actuating joint 1 .

\begin{tabular}{|c|c|c|c|c|}
\hline \multicolumn{5}{|l|}{ Sensors for the two links leg module } \\
\hline Phidgets Force Sensor for underwater detection & Ratio metric force sensor & 0.1 & 1 & $£ 6.88$ \\
\hline Interlink Electronics 0.2" Circular FSR & good for exact control applications & 0.002 & 1 & $£ 3.5$ \\
\hline Lynxmotion Hexapod Foot Sensor (Pair) & measuring leg running speed/pace and distance & 0.06 & 1 & $£ 12.1$ \\
\hline
\end{tabular}

Second, the sensors that is required for leg as shown in the following table:

Table 5b. Second bill of material for sensing sector.

Finally, the actuators for joint two and mechanical linkages:

Table 5c. Third bill of material for actuating joint 2 .

\begin{tabular}{lllll}
\hline Actuator for joint 2 and linkages & & & \\
\hline GW31ZY 14mm Shaft Turbine worm Gear Box Motor & 14RPM DC 12V & 0.36 & 1 & $£ 25.52$ \\
Lynxmotion Pan and Tilt Kit & Aluminum (Made using of two manufacturer servo brackets) & 0.05 & 1 & $£ 6$ \\
Legs Alum Alloy Hexapod & 2 DOF Leg Frame set & 0.4 & 1 & $£ 9.995$ \\
\hline
\end{tabular}




\section{Control and Analysis}

\subsection{Force Analysis}

The predictable total mass of the leg module is approximately $1 \mathrm{~kg}$.

$$
\text { Weight }=\text { mass } \times \text { acceleration }=1 \times 9.81=9.81 \mathrm{~N} \downarrow
$$

While the total designed length is $30 \mathrm{~cm}$ when the leg is extended fully (the two links are aligned to the longest reach)

Torque $=$ Force $\times$ distance $=9.81 \times 0.3=2.943 \mathrm{~N} . \mathrm{m} \downarrow$

However, if we took that the force is located in the center of the two links, the distance would be $15 \mathrm{~cm}$. Therefore, the torque required as a minimum is:

$$
\text { Torque }=\text { Force } \times \text { distance }=9.81 \times 0.15=1.4715 \mathrm{~N} . \mathrm{m}
$$

Hence, the minimum force required is $10 \mathrm{~N}$ to ensure that the leg module dos not fall.

\subsection{System Modelling and Analysis}

The electrical circuit that represents the DC motor of joint 2 is shown in figure 8 :

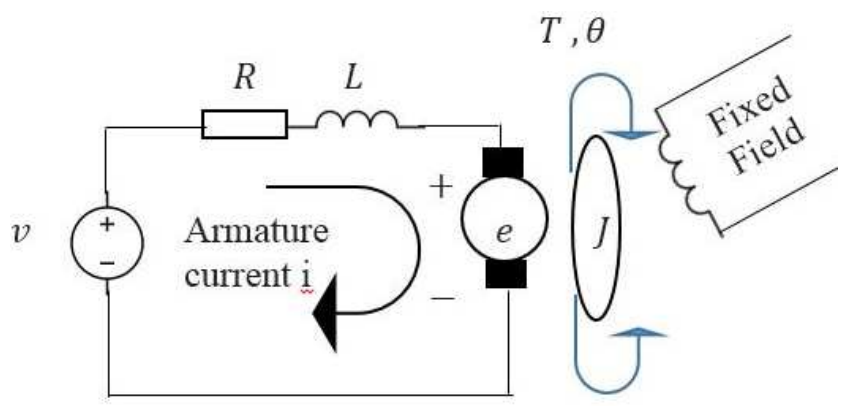

\section{$b \dot{\theta}$ \\ Rotor}

Fig. 8. DC Motor Circuit.

$J$ : inertia of joint $2 \approx 0.0225 \mathrm{~kg} \cdot \mathrm{m}^{2}$

\section{$L=43 \mathrm{mH}$ the inductance of the motor}

Newton's second law and Kirchhoff voltage law can be applied on this circuit to obtain the two following equations:

$$
\begin{gathered}
J \ddot{\theta}+C t \dot{\theta}=K i \\
L \frac{d i}{d t}+R i=V-K \dot{\theta}
\end{gathered}
$$

The torque of the motor is directly proportional to the flow current:

$$
\begin{gathered}
T=K i \\
T=\dot{\theta} \times J
\end{gathered}
$$

$\mathrm{K}$ : denotes the motor constant and rotational stiffness

$$
C t: \text { damping coefficient }=2.8 \mathrm{Nms} / \mathrm{rad}
$$

After taking Laplace transform for the above four equations and substitute one inside each other, It will end up with the two transfer functions:

$$
\begin{gathered}
G_{1}(s)=\frac{T(s)}{\theta(s)}=\frac{1}{J s^{2}+C t s+K} \frac{N \cdot m}{r a d} \\
G_{2}(s)=\frac{\theta(s)}{V}=\frac{K}{s\left((J s+C t)(L s+R)+K^{2}\right)} \frac{r a d}{V}
\end{gathered}
$$

The open loop transfer function $G_{1}(s)$ can be obtained by entering the values of (moment of inertia $\mathrm{J}$, damping $\mathrm{Ct}$ and rotational stiffness) into MATALB. The response wave form depends on the estimated values of J, Ct and stiffness. Since the system does not have stiffness, third term of the denominator of G1(s) will be zero. Consequently, the final transfer function that will be examined is:

$$
G_{1}(s)=\frac{T(s)}{\theta(s)}=\frac{1}{J s^{2}+C t s} \frac{N \cdot m}{\mathrm{rad}}
$$

\subsection{Open Loop Response}

In the open loop scheme, the parameter, which is required such as the angle $\theta$, is adjusted manually by the operator through changing the input torque which varies proportionally with the current flow in the motor. Another aspect of open loop system is the continuity observation which may lead to overshoot [9]. The response for this system is shown below:

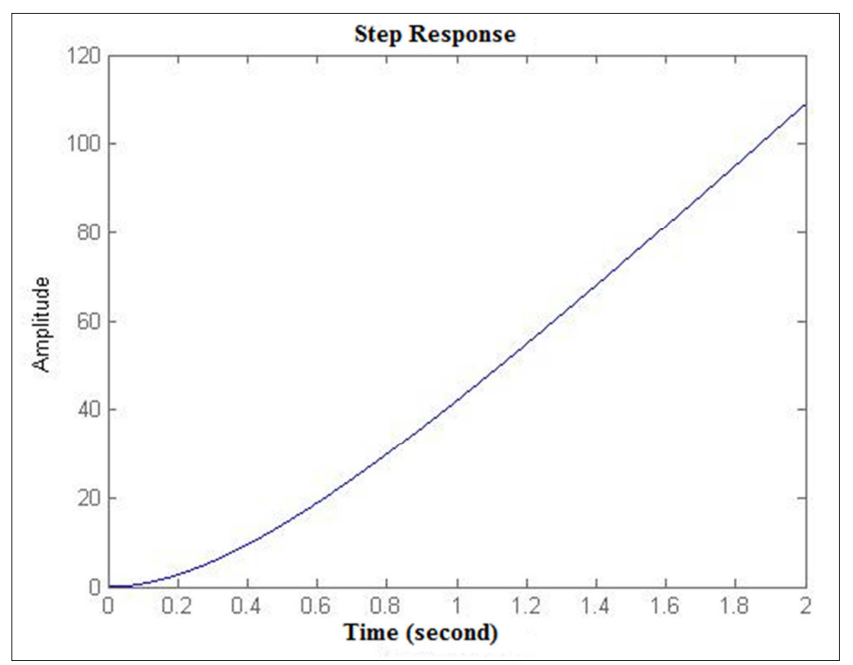

Fig. 9. Step response of $G 1(s)$.

From the above plot, it is clear that when 1 N.m is applied as an input torque the position of the motor in terms of rad raises unrestrainedly. In particular, the steady state error seems to be zero. However, it is not stable as well. To this end, the command 'isstable' is used to indicate that the system is stable or not. In order to achieve the best response, closed loop model must be applied as shown in the block diagram below: 


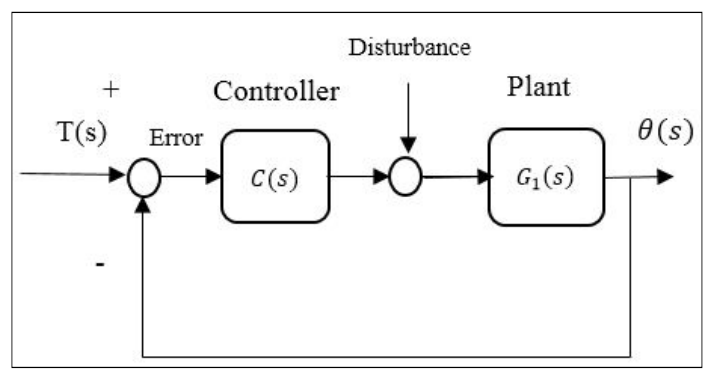

Fig. 10. Feedback system model.

The main advantage of closed loop system is to observe the actual output $(\theta)$ with the desired, and the error signal will enter the controller to perform the correction required. This process will continue till the error signal becomes zero. The closed loop (feedback system) response with only proportional controller $(\mathrm{KP}=1)$ is:

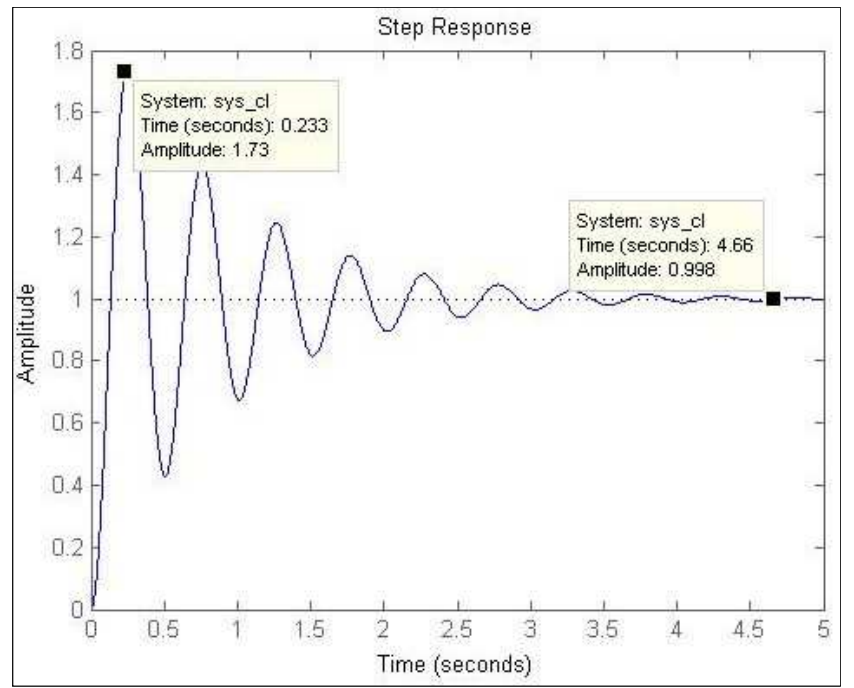

Fig. 11. Feedback system step response with $K P=1$.

It is obvious that the response has overshoot that means that the actual output goes up and down of the desired value as shown. In addition, the steady state condition realizes after 4 minutes (settling time $=4 \mathrm{sec}$ ). To obtain the best response PID is the appropriate controller that takes the advantages of Proportional, Integral and Derivative controllers.

\subsection{PID Controller Design}

The transfer function of the PID controller can be presented as:

$$
C(s)=K p+\frac{K I}{s}+K_{d} s=\frac{K_{d} s^{2}+K p s+K I}{s}
$$

This transfer function is multiplied by $G_{1}(s)=\frac{1}{J s^{2}+C t s}$. In order to see smooth response without overshoot and small settling time, three factors must be tuned carefully. First, the proportional controller (KP) which is responsible for tolerating continuous cycling of the system is tuned. The second term integral (KI) is used with proportional to reset the steady state error to zero. Finally, derivative part is employed for stability issues such as reducing overshoot and rise time.

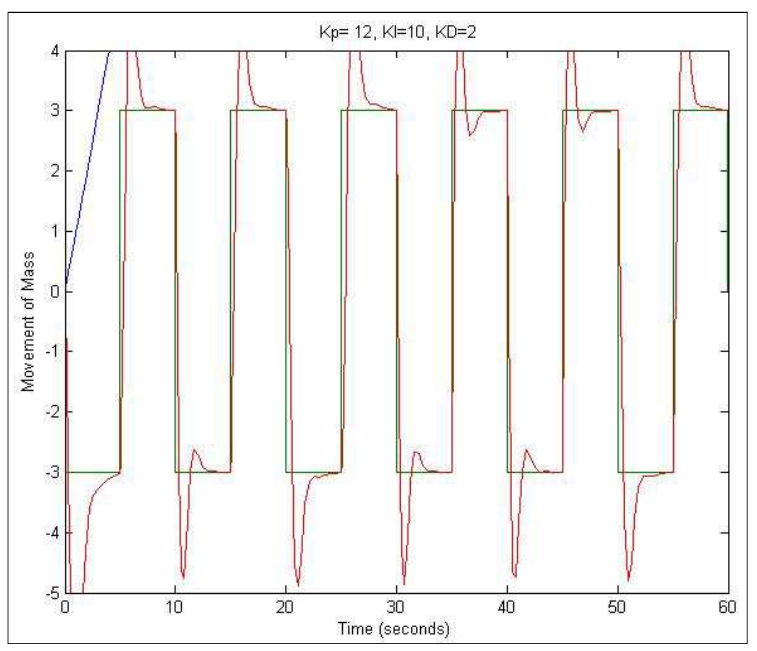

Fig. 12. First try of tuning at $K P=12, K I=10$ and $K D=2$.

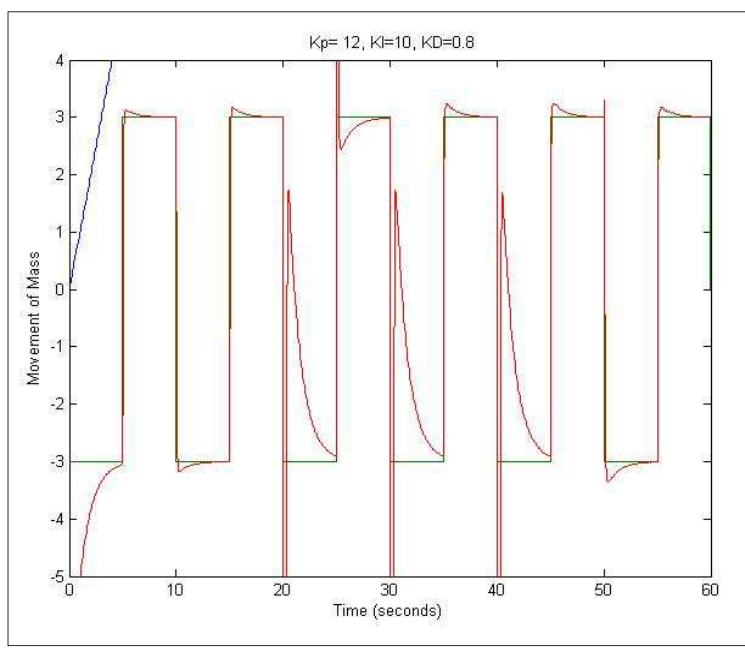

At $\mathrm{KP}=12, \mathrm{KI}=10$ and $\mathrm{KD}=0.8$

Fig. 13. Second attempt of tuning PID controller.

Just by reducing the derivative controller 0.01 the sparks of actuator saturation becomes much better as shown:

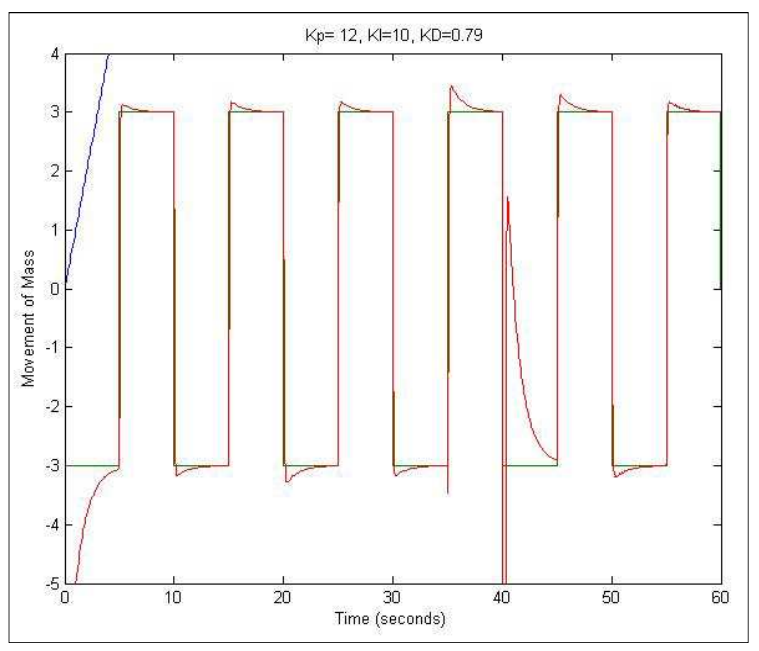

At $\mathrm{KP}=12, \mathrm{KI}=10$ and $\mathrm{KD}=0.79$

Fig. 14. Third attempt of tuning PID controller. 


\section{Conclusion}

In this paper, the leg of a hexapod underwater robot has been designed by Solidworks.

The solution, which is found for the two links leg to be compatible with working underwater, is the worm shaft and gear. This add-in design moved the motor of the joint two away from the elbow that usually used to use motor at each joint. Eventually, combination between underwater walking robot leg design and underwater inspection robot leg has can be accomplished.

The kinematic results from Denavit - Hartenberg notation have been presented in MATLAB workspace.

PID controller design for joint 2 had a lion's share of this work. Manual tuning of PID parameters was the approach to achieving the best performance of the closed loop system of joint 2. The results of tuning have provided much better response out of three rounds. The first attempt had high overshoot with zero stead sate error while the second one had very little overshoot with multi saturation sparks. Finally, by tuned KD the sparks has been reduced to minimum but it is still found. Consequently, the saturation of actuator cannot be eliminated completely because the actuator very small to implement large control exertion. Thus, to cancel reset windup we should use other sizes of actuator (motor) to ensure that the integral action can eliminate not only steady state error but also this effect.

\section{References}

[1] Tedeschi, F., \& Carbone, G. Towards the design of a leg-wheel walking hexapod. In Mechatronic and Embedded Systems and Applications (MESA), 2014 IEEE/ASME 10th International Conference, 10-12 Sept. 2014, Senigallia. IEEE, 2014, (pp. 1-6).

[2] Hodoshima, Ryuichi, et al. Development of ASURA I: Harvestman-like hexapod walking robot — Approach for long-legged robot and leg mechanism design. In Intelligent Robots and Systems (IROS), 2013 IEEE/RSJ International Conference, 3-7 Nov. 2013, Tokyo. IEEE, 2013, (pp. 4669-4674).
[3] Evangelista, \& Guillermo. Design and modeling of a mobile research platform based on hexapod robot with embedded system and interactive control. In Methods and Models in Automation and Robotics (MMAR), 2014 19th International Conference, 2-5 Sept. 2014, Miedzyzdroje, Poland. IEEE, 2014, (pp. 294-299).

[4] Jung-Yup Kim \& Bong-Huan Jun. Design of six-legged walking robot, Little Crabster for underwater walking and operation. Advanced Robotics. 2014, 28 (2), pp. 294-299.

[5] Hee Jong Kim et al. Multi-functional bio-inspired leg for underwater robots. Intelligent Robots and Systems (IROS 2014), 2014 IEEE/RSJ International Conference, 14-18 Sept. 2014, Chicago, IL. IEEE. (pp. 1087-1092).

[6] Green Mechanic. Advantages and Disadvantages of Different Types of Gears: [Online]. 2013. [05/01/2015]. Available from: http://www.green-mechanic.com/2014/05/advantages-and-disa dvantages-of_7.html.

[7] IEN. Advantages of Worm Gear Reducers. [Online]. 2013. [05/01/2015]. Available from: http://www.ien.com/article/advantages-worm-gear/173134.

[8] RC Helicopter Fun. Digital RC Servos vs. Analog RC Servos. [Online]. 2008-2015. [07/01/2015]. Available from: http://www.rchelicopterfun.com/rc-servos.html

[9] Woodbank Communications Ltd. Electric Drives - Motor Controllers and Control Systems. [Online]. 2005. [Accessed 14 December 2014]. Available from: http://www.mpoweruk.com/motorcontrols.htm

\section{Biography}

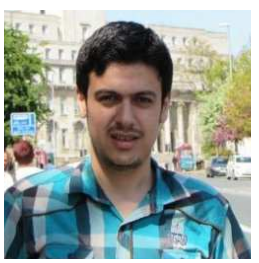

Yazen H. Shakir graduated from Mosul University in Iraq, BSc Mechatronics Engineering (2006-2010). He studies MSc Mechatronics and Robotics in Leeds University in the UK. He currently lives in Iraq. 